
IP Periodica Polytechnica
Civil Engineering

61(1), pp. 98-109, 2017

DOI: $10.3311 /$ PPci.9257

Creative Commons Attribution (i)

RESEARCH ARTICLE

\section{Numerical Simulation of Welding Process - Application in Buckling Analysis}

\author{
Dénes Kollár ${ }^{1}$, Balázs Kövesdi ${ }^{1 *}$, János Nézö ${ }^{2}$
}

Received 30-03-2016; revised 09-05-2016; accepted 10-05-2016

\begin{abstract}
Numerical simulations make the improvement of fabrication process and welding technology. Numerical simulations make the improvement of fabrication process and welding technology possible. Using finite element method the most important information about welded specimens can be determined such as deformed shape, residual stresses or even microstructural properties like phase proportions or hardness. The current study focuses on the modelling background of welding processes and the effects of different welding parameters on residual stresses and deformations. The paper focuses on heat sources, temperature dependent material properties and the development of a thermo-mechanical analysis. The virtually fabricated specimens are further analysed to investigate the stability behaviour.
\end{abstract}

\section{Keywords}

welding simulation, residual stresses, residual deformations, uncoupled thermo-mechanical analysis, GMNI analysis

\section{Introduction}

It is a fundamental expectation to speed up manufacturing processes while improving productivity and quality of steel structures. Structural steels are among the most widely used structural materials in the civil engineering practice. Welding has become more relevant for on-site constructions while it has been already widely used in workshops in the steel industry. Therefore it is an important task to determine residual deformations and residual stresses due to welding since it can have influence on the quality of the manufacturing process as well as on the resistance of steel members. Numerous previous research activities highlighted the importance of residual stresses and geometric imperfections. Detailed experimental investigations were carried out on welded and cold-formed box section girders by Somodi and Kövesdi in 2015 [1] to investigate the shape and magnitude of the residual stresses in different box sections using different steel grades. Results of previous laboratory tests showed that the shape and the residual stress intensity appreciably depend on the manufacturing process and the geometry of the specimen. However most of the standards such as the Eurocode [2] give only approximations and assumptions on initial geometric imperfections while the real behaviour of the analysed structures can be significantly different. On the other hand, in case of steel structures there are often manufacturing difficulties and resistance problems due to large weld sizes and high heat inputs. These effects can result in large deformations and residual stresses, which can reduce the resistance of the steel members for example for bridges where the applied plate thicknesses can be quite large (up to $100 \mathrm{~mm}$ ).

The development of production quality and design of sustainable structures indicate the importance of numerical simulations. Finite element analysis can be used to design structures considering the manufacturing process as well. Several years ago it was almost impossible to simulate the welding of complex structures because of hardware requirements and long computational time. Due to the improvement of computational background it is feasible to examine large-scale welded joints and structures in an adequately accurate way, but it has to be declared that computations still have limitations. 
A reliable numerical design approach is presented in the current paper using the finite element program ANSYS 14.5 [3] to take the effect of the welding procedure into consideration. Based on a deep literature overview [4-7] different heat sources, temperature dependent material properties, boundary conditions and analysis types are investigated and compared. Based on own laboratory tests on temperature and residual stress measurements the developed numerical simulation technique is verified. For the welding simulation an uncoupled thermo-mechanical analysis is used to determine temperature fields, deformations and residual stresses. The welding simulation process is fully automated, running step by step while the heat source (i.e., the welding torch) is moving forward. After the numerical simulation the deformed shape and the residual stress state of the specimen is determined and the virtually fabricated structure is ready for further analyses such as buckling or fatigue analysis.

In this paper several numerical results of butt welded plates and box sections are introduced as parts of a general research program (Fig. 1). As a first step the research work focuses on the determination of residual stresses and deformations due to different welding parameters. On the other hand, the local buckling behaviour has a significant importance in the civil engineering practice therefore an example is also presented in the current paper on a stub column specimen with box section.

a)

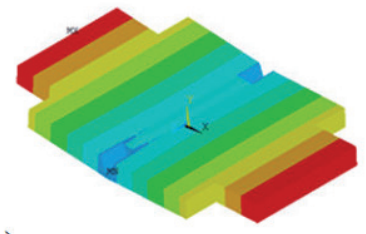

Fig. 1 Deformed shapes of modelled geometries: a) butt welded plate, b) box section

\section{Applied simulation technique}

Welding process is a complex thermo-mechanical progress that needs multidisciplinary knowledge. The most important relations between each discipline are shown in Fig. 2. The marked numbers mean the following relations according to $[8,9]$ :

1a thermal strains are the function of microstructural changes,

1b elastic/plastic behaviour based on steel microstructure,

1c volumetric changes due to phase transformation,

1d plastic strain coupled with microstructural changes,

2a thermal material properties are the functions of microstructure,

$2 \mathrm{~b}$ latent heat due to phase transformations,

$2 \mathrm{c}$ latent heat due to solid to liquid phase changes,

3a thermal boundary condition change due to deformation evolution,
$3 \mathrm{~b}$ heat generation due to elastic/plastic/thermal strains, 4a microstructural evolution is based on deformations, $4 \mathrm{~b}$ stress state has an influence on phase transformations, 5 microstructure depends on heating and cooling rate, 6 temperature changes cause deformations.

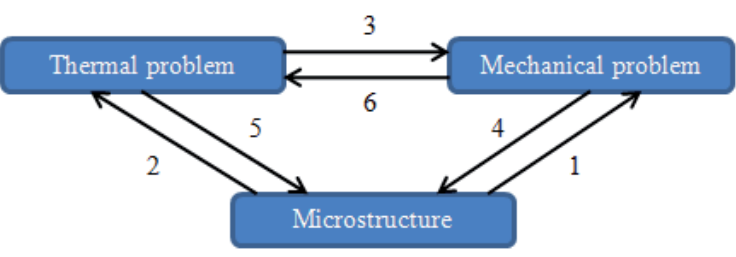

Fig. 2 Multidisciplinary relations for welding simulations [8, 9]

In the current research program an uncoupled thermomechanical analysis is carried out, where the main part of the relations are simplified. The current investigation focuses on arc welding and laser welding. Based on previous investigations [7] it can be concluded, that a coupled analysis is only necessary, if friction stir welding is simulated. For arc and laser welding the uncoupled analysis technique gives also appropriate results. It means that in the developed numerical model the temperature fields are determined first during welding while in the mechanical analysis the temperature fields are applied as nodal loads. The problem is solved step by step while the heat source is moving during the welding process. Solid elements are applied in welding simulations, it is especially important to have a dense solid mesh in the heat affected zone where the thermal gradient could be quite high thus it is possible to follow the residual stress and microstructural changes with large accuracy. Far from the welding path it is enough to use a coarser mesh. The solid model is meshed with appropriate thermal brick elements. The applied elements are 20-node 3D solid elements that have to be transferred to their alternative equivalent structural elements at the beginning of the mechanical analysis. Tetrahedral elements are not recommended for thermomechanical analysis because they have only one integration point, therefore they are not applied in the current analysis.

\section{Material models and modelling techniques 3.1 Heat source models}

Depending on the welding process an adequate heat source model has to be defined for the numerical simulation. Basically there are two possibilities found in the international literature, which are shown in Fig. 3.
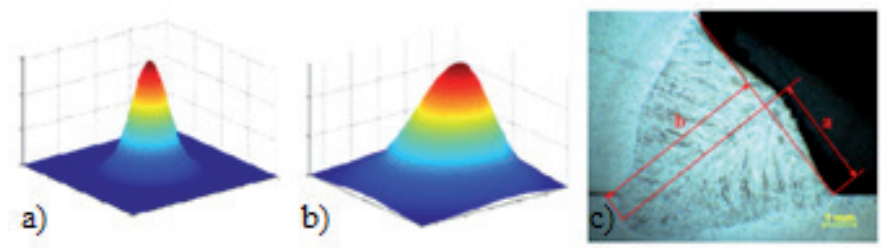

Fig. 3 a) 3D Gaussian heat source, b) Goldak's double ellipsoidal heat source model, c) macrograph with heat source parameters [10] 
The 3D Gaussian heat source model is applied for modelling electron beam or laser welding, while Goldak's double ellipsoidal heat source model is typically used for arc welding. In this case the front and rear ellipsoid could be calibrated and fitted separately based on macrographs (Fig. 3c), so the heat source can be applied even to simulate deep penetration welding. The heat input is given by Eq. (1), where $\eta$ is the welding efficiency, $U$ is the voltage and $I$ is the current.

$$
Q=\eta U I
$$

The heat density of the 3D Gaussian heat source model is determined by Eq. (2) while in case of Goldak's double ellipsoidal heat source model it may be described Eq. (3):

$$
\begin{gathered}
q(r, y)=Q_{0} e^{-3 r^{2} / r_{0}(y)^{2}} \\
q_{f}(w, y, z)=Q_{0, f} e\left(-3 \frac{x^{2}}{a^{2}}\right) e\left(-3 \frac{y^{2}}{b^{2}}\right) e\left(-3 \frac{z^{2}}{c_{f}^{2}}\right)
\end{gathered}
$$

where $r$ is the current radius from the center of the heat source, $r_{0}(y)$ is the radius of heat source at $z$ coordinate. The $q_{f}$ is the heat source density of the front ellipsoid, $a$ is the half width of the heat source model, $b$ is the penetration and $c_{f}$ is the length of the front ellipsoid. The parameter $c_{r}$ is twice as long as $c_{f}$. The heat source model definition for the rear ellipsoid is done by changing the indices according to [12]. $Q_{0}, Q_{0, f}$ and $Q_{0, r}$ have to be calibrated during the thermal analysis to ensure, that the transmitted heat input is equal to $Q$ given in Eq. (1) in all time steps when the heat source is applied on the specimen. The detailed description of this heat source model can be found in [11].
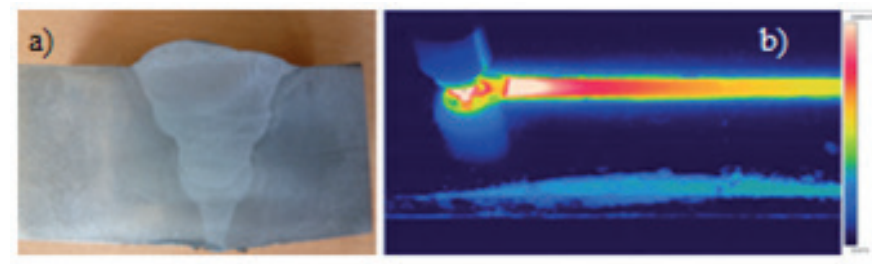

Fig. 4 a) Macrograph of a multi-pass butt welded plate, b) picture of a thermographic camera [13]

The determination of welding efficiency is not a simple task because this effect is included in the heat input. Basically there are two methods to calibrate the thermal models. First of all macrographs are used to evaluate the size of the heat affected zone while temperature measurements are usually performed by thermocouples or thermographic cameras to determine efficiency in a much accurate way (Fig. 4). Both of the experiments can help to define the correct heat source parameters.

\subsection{Thermal boundary conditions}

Several input parameters have to be added during the thermal analysis to describe the boundary conditions. The initial temperature of the specimen and the ambient temperature have a significant role during the heating and cooling phases. The heat transfer phenomenon is divided into two parts: convection and radiation. The heat transfer could be modelled by different ways in the numerical models. The usually applied opportunities are heat exchange surfaces defined by surface elements or surface loads acting on nodes. The convective heat transfer coefficient is taken equal to $25 \mathrm{~W} /\left(\mathrm{m}^{2} \cdot \mathrm{K}\right)$. The emissivity coefficient $(\varepsilon)$ is assumed to be 0.8 while the ambient temperature $\left(T_{a m b}\right)$ has to be defined for radiation as well. The radiative heat transfer coefficient is described by Eq. (4):

$$
h_{r}(T)=\varepsilon \cdot F_{i j} \cdot \sigma \cdot\left(T+T_{a m b}\right) \cdot\left(T^{2}+T_{a m b}^{2}\right)
$$

where $F_{i j}$ means the view factor which is equal to $1, \sigma$ is the Stefan-Boltzmann constant having the value of $5.67 \cdot 10^{-8} \mathrm{~W} /$ $\left(m^{2} \cdot K^{4}\right)$ while $T$ is the specimen's temperature. Temperatures are absolute temperatures in $\mathrm{K}$ in the given equation.

It is a time-effective way to handle symmetric problems by defining planes of symmetry. It means that in a thermal analysis no heat exchange surface has to be modelled in the planes of symmetry, therefore no heat flux could transfer through this surface. There are several further difficulties using plane symmetry, for example modelling the welding path and the heat source, as shown in Fig. 5.

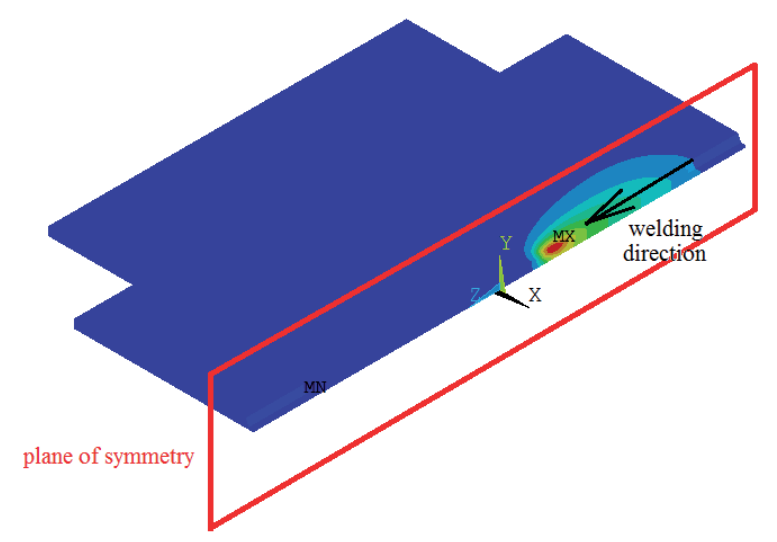

Fig. 5 Using plane symmetry of a butt welded plate in the thermal analysis

\subsection{Thermal material model}

The applied material properties are based on the EN19931-2 [14] for structural steel S355 in the current investigations. It is a widely used material so it is appropriate for verification purposes. The code is basically recommended for structural fire design but there are numerous previous research results which show its applicability for welding simulation purposes as well [7, 15]. According to the EN 1993-1-2 the maximum recommended thermal gradient is $50^{\circ} \mathrm{C} / \mathrm{s}$ which is a good assumption for the phenomena of fire. In case of welding underestimation of the cooling and heating rates is possible in the heat affected zone (HAZ) which has a large effect on the phase transformations. The microstructural changes and phase proportion evolutions are not included in the standard - except for the temperature 
dependent specific heat - but it can still be applied for welding simulations. There are several thermal material properties to be defined for analysing thermal problems. The density of steel is not considered as temperature dependent so it is taken as a constant in the simulations with an intensity of $7850 \mathrm{~kg} / \mathrm{m}^{3}$. It is an approximation because actually the volume of the material increases during heating while its density decreases. It is possible to take this effect into account in the model but it does not have significant influence in case of welding therefore it is neglected in the current calculations. The temperature dependent specific heat has a high peak value at $735^{\circ} \mathrm{C}$ that describes the phase transformations between $\alpha$-iron and $\gamma$-iron. Specific heat is supposed to be constant after $1200^{\circ} \mathrm{C}$. Temperatures can be higher in case of welding with melting of the material. The latent heat can be taken into account using the effective specific heat given in Eq. (5) proposed by [16]. This effective specific heat is implemented in the developed numerical model.

$$
c_{\text {eff }}(T)=\left\{\begin{array}{c}
c_{s}, T<T_{s} \\
c_{s}+\frac{L}{T_{l}-T_{s}} \frac{T-T_{s}}{T_{l}-T_{s}}, T \leq T \leq T_{l} \\
c_{l}, T>T_{s}
\end{array}\right.
$$

where $T_{s}$ is the solidus temperature, $T_{l}$ is the liquidus temperature, $L$ is the latent heat while $c_{s}$ and $c_{l}$ are the solidus and liquidus specific heat. The determination of $T_{s}$ and $T_{l}$ are given by Eq. (6) and (7) according to [5] in the function of carbon content.

$$
\begin{gathered}
T_{s}=1527-181.356 C \\
T_{l}=1530-80.581 C
\end{gathered}
$$

Rapid changes in the effective specific heat curve are recommended to model by applying enthalpy to avoid numerical problems [16]. Enthalpy is defined by Eq. (8).

$$
H(T)=\int_{0}^{T} \rho(T) c(T) d T
$$

Thermal conductivity has a major importance in the calculation process because it has the same role in the finite element method as the Young's modulus in structural analysis as it defines the stiffness matrix of the thermal analysis. The applied thermal material properties in the numerical simulations are shown in Fig. 6.

\subsection{Mechanical boundary conditions}

In the mechanical analysis the clamping conditions (i.e., degrees of freedom constraints) have an important influence on the evolution of deformations and stresses. Even changing the time of unclamping has an appreciable influence on the residual stresses and deformations. It is obvious that the stiffer the clamping conditions are, the smaller the induced residual deformations are while the stresses are higher. The optimization of the stress-deformation relationship is an important task.
First of all rigid body motion has to be avoided. Therefore tack welds or linking plates should be added if the supports have translational degrees of freedom. Otherwise clamps fundamentally act like rigid supports. It means it does not have rotational degrees of freedom. In this case no other miscellaneous action (such as tack welds, etc.) has to be modelled. If a symmetric problem is studied, the nodes have to be supported in the normal direction of the plane of symmetry in the mechanical analysis. This technique is time-saving and useful when modelling large structures. An example is shown in Fig. 7 with free transversal and longitudinal motion.
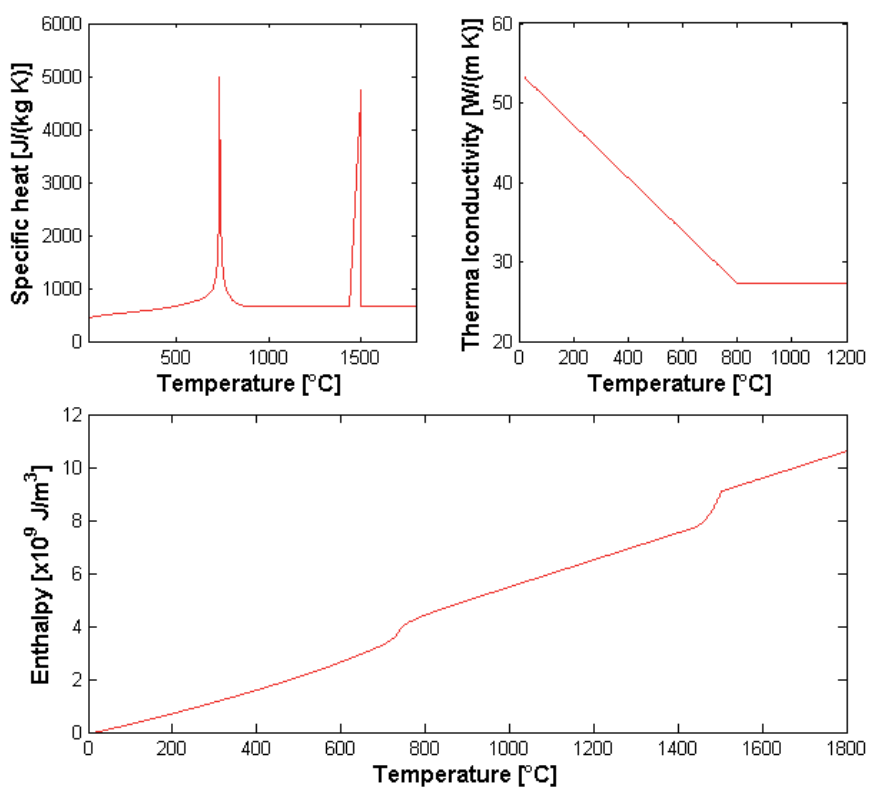

Fig. 6 Thermal material properties of steel according to [14]

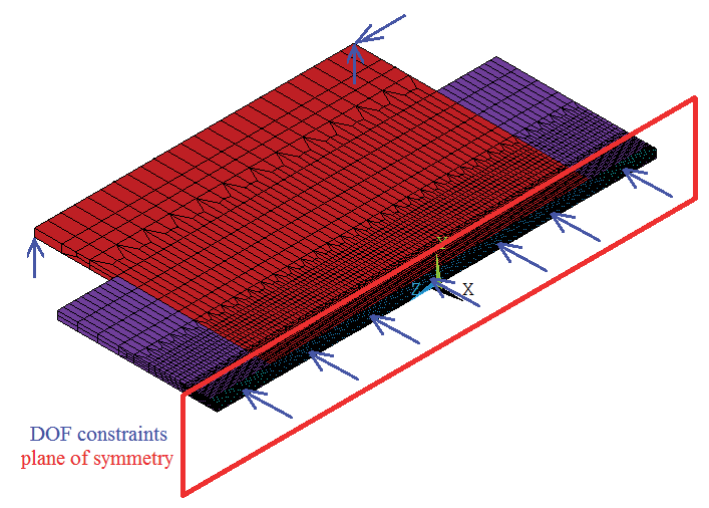

Fig. 7 Using plane symmetry of a butt welded plate in the mechanical analysis

\subsection{Mechanical material properties}

The following material properties have to be added to simulate a mechanical problem: Poisson's ratio, thermal strain, Young's modulus, yield strength and stress-strain curves. The Poisson's ratio is taken as constant, its value is 0.3 . The Eurocode gives a curve for thermal strains (Fig. 8) with a reference temperature $\left(T_{r e f}\right)$ of $20^{\circ} \mathrm{C}$. Thermal strains can be calculated by Eq. (9): 


$$
\varepsilon_{\text {ther }}(T)=\frac{\Delta l}{l}(T)=\alpha(T) \cdot\left(T-T_{r e f}\right)
$$

where $\alpha(T)$ is the temperature dependent secant coefficient of thermal expansion. The temperature dependent mechanical material properties are defined via reduction factors (Fig. 8). The initial value of Young's modulus is $210 \mathrm{GPa}$ on room temperature while the yield strength of S355 steel material is 355 MPa. The reduction factor curves for effective yield strength $\left(k_{y, \theta}=f_{y, \theta} / f_{y}\right)$, proportional limit $\left(k_{p, \theta}=f_{p, \theta} / f_{y}\right)$ and Young's modulus $\left(k_{E, \theta}=E_{a, \theta} / E_{a}\right)$ are shown in Fig. 8 in the function of the temperature.
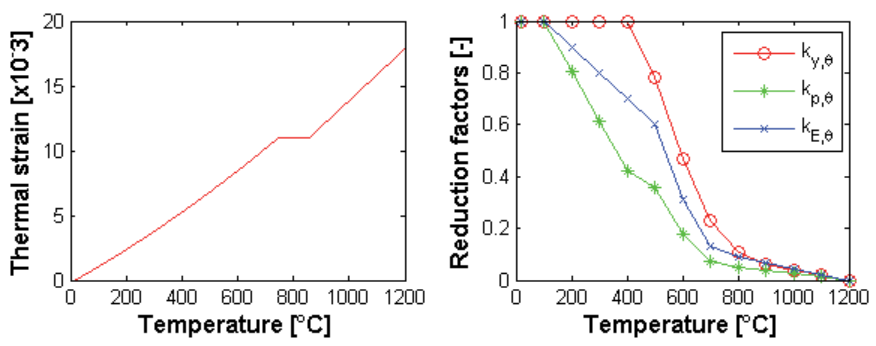

Fig. 8 Thermal strain (on the left) and reduction factors (on the right)

Figure 8 shows that the stiffness of the steel material decreases rapidly while temperature increases. Above $1200^{\circ} \mathrm{C}$ the Eurocode assumes that the stress induced in the material is zero. According to [12] this critical temperature should be called zero strength temperature (ZST). It is important to understand that elements with small stiffness could cause convergence and element distortion problems. Therefore these elements have to be 'killed' during the analysis if their temperature is above the ZST. It means that their stiffness is reduced radically and their strains and stresses are zeroed out. If the element cools below the ZST again it will be activated and its stress-strain history is started from zero again. After the activation the reference temperature is changed from room temperature to ZST so the thermal elongations will behave normally. This special modelling technique is the so called 'birth and death' method. In our study ZST is set to $1200^{\circ} \mathrm{C}$.

The required parameters for stress-strain curve calculations are given in the EN1993-1-2 [8]. The code gives a recommendation for hardening below $400{ }^{\circ} \mathrm{C}$ in Annex A. Typical stressstrain curves are shown for S355 in Fig. 10, which are used in the current simulations. The permitted hardening rate is 25 percent of the yield strength. A multi-linear isotropic hardening model is used in the current simulations. Welding causes massive thermal cycles in the material therefore in a few cases kinematic hardening should be applied, however the isotropic hardening model is also accepted for welding simulations [12, 17-19]. The kinematic hardening model is especially recommended for fatigue analysis.

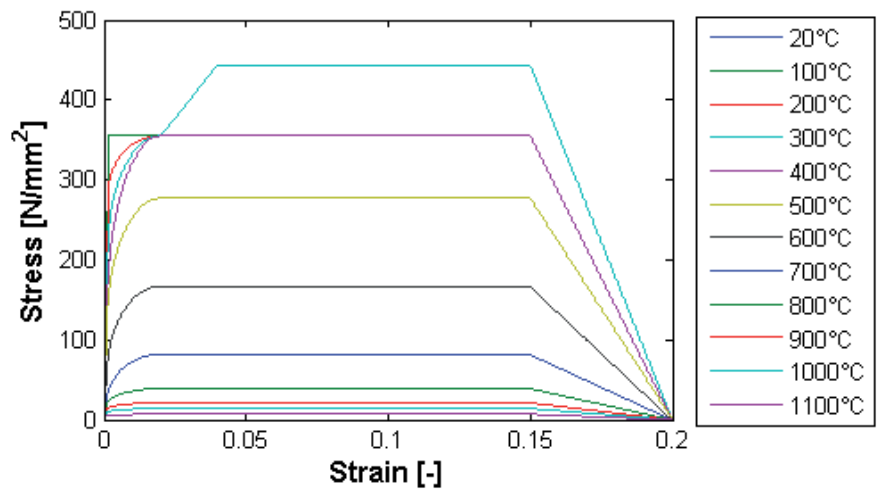

Fig. 9 Applied stress-strain curves for structural steel S355

\section{Simulation results}

\subsection{Model verification by another numerical model}

At first the results of the numerical calculations are compared to the results of an independent software called SYSWELD [20]. The thermal analysis is carried out in both FE codes with the same butt welded plate geometry, FE mesh size (Fig. 10), heat source parameters and boundary conditions, as presented in [21]. The results of the thermal analyses are compared and all the differences between the two models are discussed and evaluated.

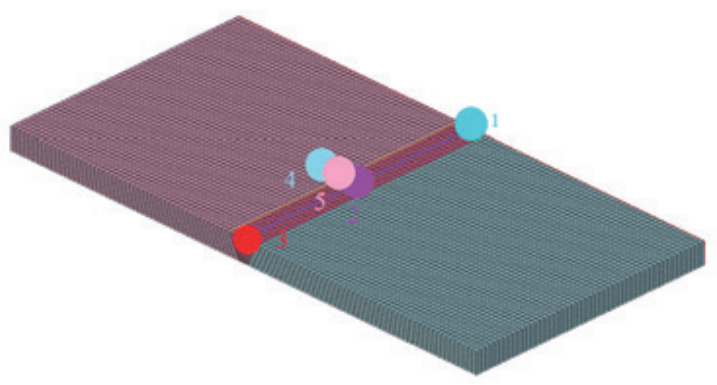

Fig. 10 Reference model of butt welded plate in SYSWELD with reference nodes

Only the initial thermal properties of ferrite are used in the model and changed the material to austenite above the $\mathrm{Ac}_{3}$ upper temperature of austenitization. The thermal material properties are quite similar for each phases defined in the database [20] except the range between room temperature and 900 ${ }^{\circ} \mathrm{C}$, where the austenitic phase does not have a peak in the specific heat curve. The density of austenite is also a little different, but it has to be clear that the enthalpy difference does not have a large effect on thermal results because the heat source and the heated amount of material is negligible compared with the size of the welded plates.

The comparison of the results calculated by the two models is shown in Fig. 11. The results show that the temperaturetime curves of the reference nodes are in good agreement with the results of our ANSYS model. The temperature of the node marked by ' 1 ' increases rapidly as the heat source appears on the plate. As time goes by the welding torch moves forward and the temperature of other reference nodes starts to increase as 
well while the nodal temperature of ' 1 ' decreases as the specimen starts to cool down. The maximum temperature came up at node ' 3 '. Based on the verification using an independent software tool it can be concluded that the developed numerical model can simulate the thermal phenomena of the heat transfer and conduction with large accuracy.

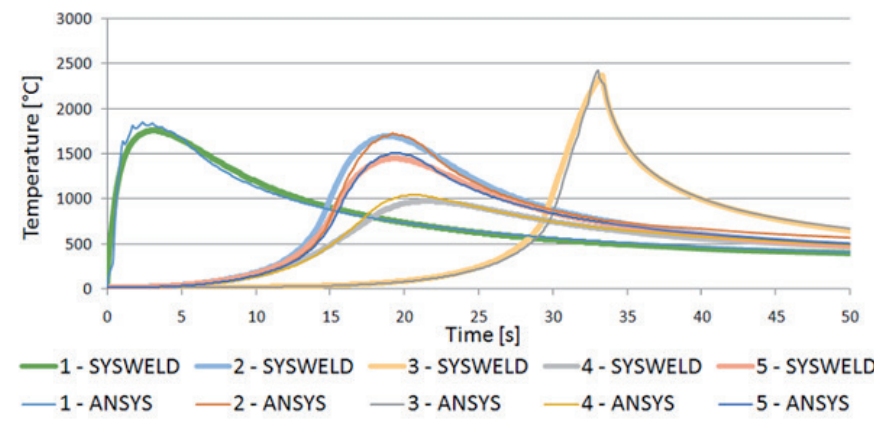

Fig. 11 Verification of the numerical model by temperature curves

\subsection{Verification by test results}

Multi-pass butt welded plates are also studied experimentally and numerically at the Budapest University of Technology and Economics. The investigated specimens are welded using Metal Active Gas (MAG) welding with four layers (one pass per layer). The analysed specimen is a butt welded plate with a thickness of $16 \mathrm{~mm}$. The width of the specimen is $120 \mathrm{~mm}$ for both plates welded together. The length of the specimen is 700 $\mathrm{mm}$, which has great importance by the determination of the residual stresses. The $\mathrm{V}$ groove weld's edges are prepared with a groove angle of $50^{\circ}$ while the root face is $2 \mathrm{~mm}$ and the root opening is $3 \mathrm{~mm}$. Run-in and run-off plates are also modelled with dimensions of $160 \mathrm{~mm} \times 80 \mathrm{~mm} \times 16 \mathrm{~mm}$. The welding parameters used in the experiment are summarized in Table 1 where 'Welding start' and 'Welding end' mean the time limits for each weld pass. Temperature measurements are executed on the test specimens during welding and residual stress measurements are executed on the prepared specimens after welding.

Table 1 Welding parameters used in the experiment

\begin{tabular}{lllllll}
\hline $\begin{array}{l}\text { Weld } \\
\text { pass }\end{array}$ & Process & $\begin{array}{l}\text { Current } \\
{[\mathrm{A}]}\end{array}$ & $\begin{array}{l}\text { Voltage } \\
{[\mathrm{V}]}\end{array}$ & $\begin{array}{l}\text { Speed } \\
{[\mathrm{mm} / \mathrm{min}]}\end{array}$ & $\begin{array}{l}\text { Welding } \\
\text { start }[\mathrm{s}]\end{array}$ & $\begin{array}{l}\text { Welding } \\
\text { end }[\mathrm{s}]\end{array}$ \\
\hline 1 & MAG & 135 & 18 & 185 & 0 & 378 \\
2 & MAG & 300 & 30 & 310 & 378 & 794 \\
3 & MAG & 300 & 30 & 310 & 794 & 1249 \\
4 & MAG & 300 & 31.5 & 235 & 1249 & 1916 \\
\hline
\end{tabular}

The locations of the strain gauges and the thermocouple are shown in Fig. 12. Based on the measurements the time - temperature curves and the residual stresses after welding are determined and compared to the results of the numerical simulations.
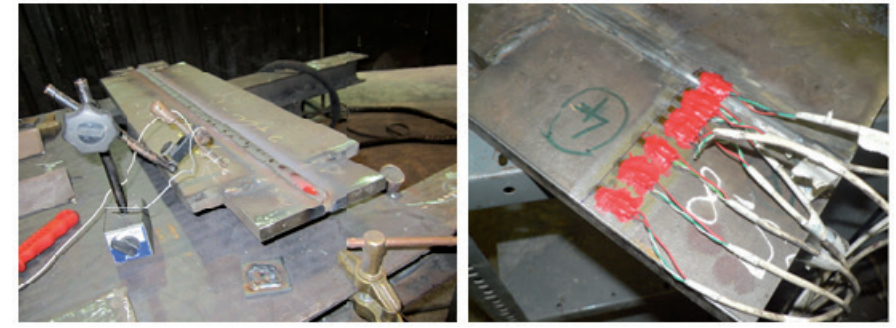

Fig. 12 Temperature measurement and strain gauges on a butt welded plate

The $\mathrm{K}$ thermocouple is located far enough from the welding path to be able to measure the temperature of the plate because its operating temperature range is between $-200{ }^{\circ} \mathrm{C}$ and $1200^{\circ} \mathrm{C}$. Residual strain measurements are also carried out in the Structural Laboratory of the Department of Structural Engineering at the BME. Detailed description of the research program and the measurements can be found in [21].

The applied finite element model and the reference node for thermal model verification are shown in Fig. 13. The reference node symbolizes the location of the $\mathrm{K}$ thermocouple. It was 38 $\mathrm{mm}$ far from edge in the longitudinal direction while the transversal distance is $69 \mathrm{~mm}$.

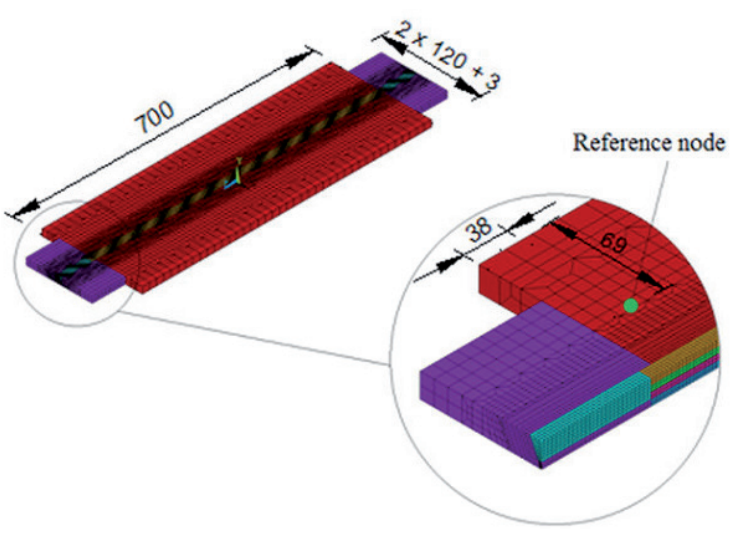

Fig. 13 Finite element model for multi-pass butt welded plate

The thermal analysis is executed using both the Eurocode and SYSWELD based material properties. It is assumed that the welding efficiency is $85 \%$. The welding parameters given in Table 1 are implemented in the numerical model. The measured and calculated time - temperature curves are compared in Fig. 14.

The results show that the time - temperature curve using the EC based material model gave results with smaller accuracy than the SYSWELD based improved material models. The difference between the two models is in the consideration of the phase transformation however both results are in good agreement with the test results. The maximum temperature per each pass increases monotonously while the ambient temperature is assumed to be constant during welding $\left(26.8^{\circ} \mathrm{C}\right)$. It can be seen that the cooling rates are getting higher for the weld passes due to the effect of radiation. 


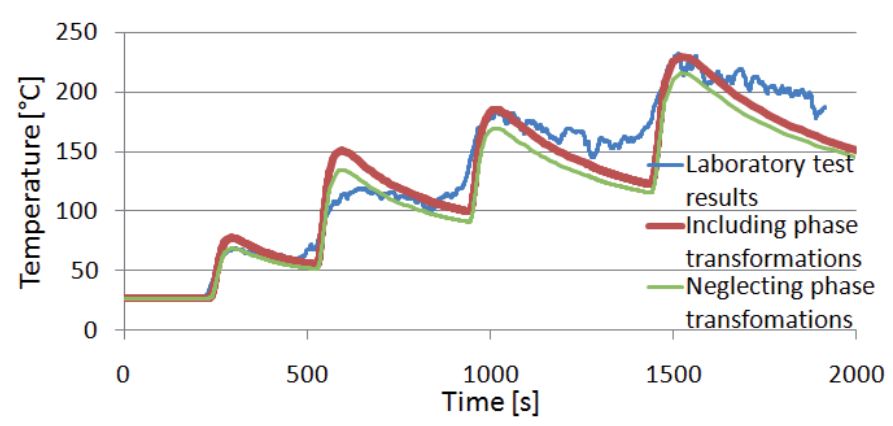

Fig. 14 Verification of the thermal simulation in the reference point

After the thermal verification the results of the mechanical analysis are also compared to the test results. Residual stress measurements are executed on the root side in a cross section located in $300 \mathrm{~mm}$ distance from the end of the specimen. There are eight strain gauges placed on the specimen and the longitudinal normal stresses are measured at these eight locations. Sectioning technique [1] is used to determine the residual stresses which are presented in Figs. 15-16.

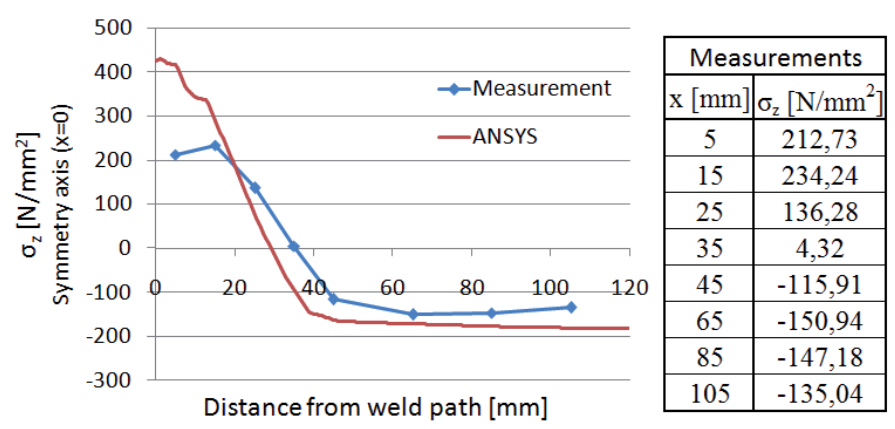

Fig. 15 Verification of the numerical model by comparison of longitudinal residual stresses

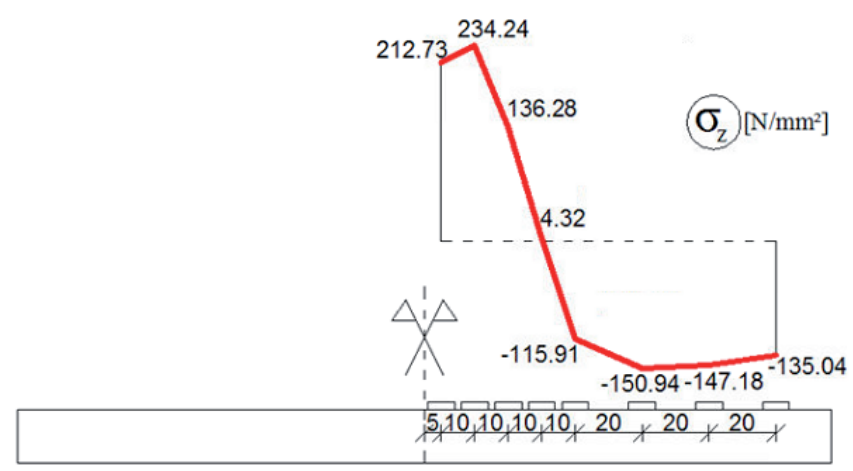

Fig. 16 Measured longitudinal residual stresses and position of strain gauges

The comparison shows that the measured and calculated longitudinal residual stresses ( $\mathrm{y}$ axis $-\sigma_{\mathrm{z}}$ ) are in good agreement except in the region of the fusion zone, where supposedly the contact between the strain gauge and the uneven surface is not perfect. The compressive residual stresses are almost constant in a relatively large region (x axis).

\subsection{Parametric studies on welding parameters}

Numerical parametric study is executed on the verified numerical model to investigate the effect of different welding parameters on the magnitude and distribution of residual stresses and remaining deformations. Only butt welded plates are analysed in this study to reduce the effect of the geometry and to emphasize the effect of welding parameters. The investigated parameters are heat input, welding speed, welding processes and steel grades. The same geometry and finite element mesh is used for the whole parametric research program as introduced in the previous chapter, to exclude all the effects of numerical modelling from the calculated results. The investigated numerical model is presented in Fig. 17. The thickness of the analysed plate is set to $4 \mathrm{~mm}$ with an equal width and length of $50 \mathrm{~mm}$. Run-in and run-off plates are added to the model to avoid rigid body motion during welding. The width of the run-in and run-off plates is $60 \mathrm{~mm}$ with a length of $15 \mathrm{~mm}$. The aim of the study is to compare residual stresses in the middle cross section of the plate perpendicular to the welding path for different welding input parameters. The presented results belong to the root side.

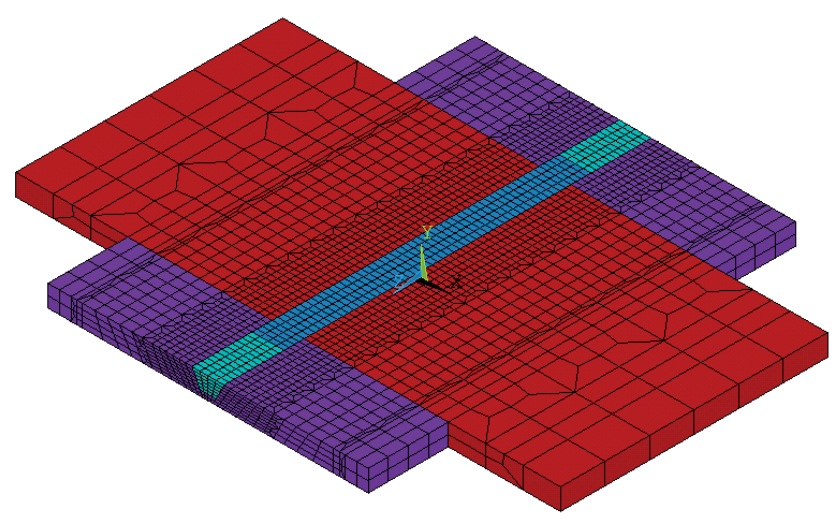

Fig. 17 Finite element model of single-pass butt welded plate for parametric studies

The reference welding parameters are summarized in Table 2 for all the three investigated parameters. The three columns (heat input, welding speed, steel grade) represent the three investigated parameters. For the three parametric studies all the calculation results are compared to the basic calculations using the reference values. Each parameter is studied using four different parameter values including the reference value.

The investigated parameters are increased by $20 \%$ steps therefore the input parameters are multiplied by 1.2, 1.4 and 1.6. In case of steel grade the following structural steel materials are investigated: S235, S355, S460 and S700. The welding parameters are unchanged during the analyses. Metal Active Gas welding is used in the numerical simulations using the following Goldak parameters: $a, b$ and $c_{f}$ values are set to a constant $5 \mathrm{~mm}$. Typical residual stress distributions for a butt welded plate are shown in Figs. 18-19 for the reference model. 
Figure 18 represents the distribution of transversal $\left(\sigma_{\mathrm{x}}\right)$ and Fig. 19 introduces longitudinal residual stresses $\left(\sigma_{z}\right)$ parallel to the welding path. There are large tensile residual stresses in the heat affected zone near the welding path, which turns into compressive stresses at the edges of the plate. The $\sigma_{x}$ transversal stresses are close to zero at the free longitudinal edges. In the corners a distracted zone can be observed due to the supports in the FE model.

Table 2 Reference welding parameters

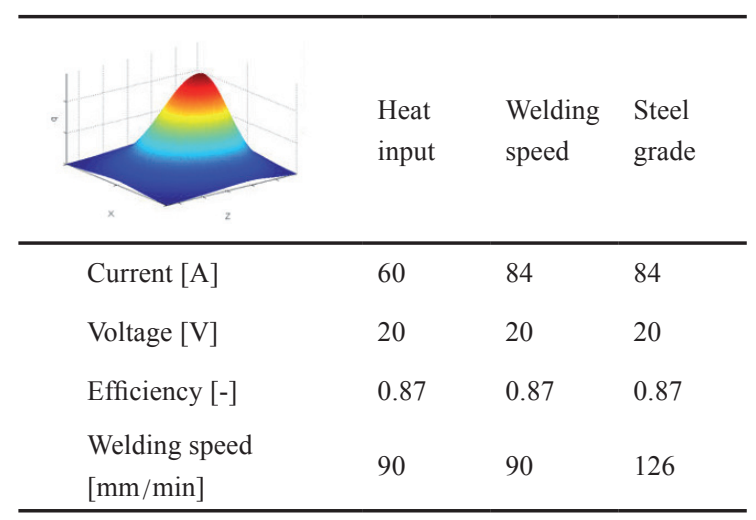

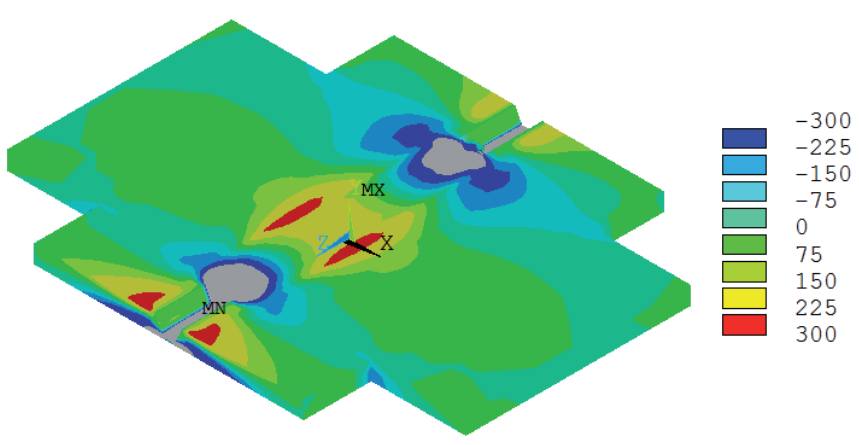

Fig. $18 \sigma_{x}$ transversal residual stresses for a butt welded plate

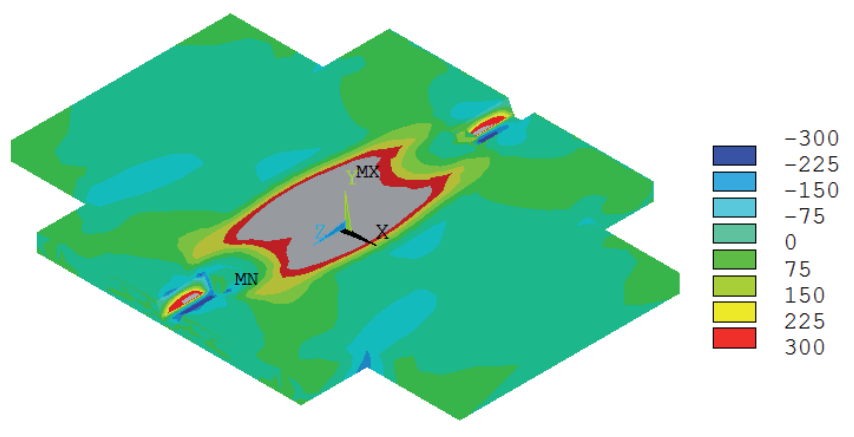

Fig. $19 \sigma_{\mathrm{z}}$ longitudinal residual stresses for a butt welded plate

After the presentation of the reference model, the results of the parametric studies are also given in diagrams. The results regarding the effect of heat input is given in Fig. 20. The results show, that heat input has large effect on the maximum tensile residual stresses and on the location of the maximum values. However it has only negligible influence on the compressive residual stresses. It means that the size of the heat affected zone is increasing by increasing heat inputs, and the peak stress decreases on the interface of the molten and stiff materials. The maximum longitudinal residual stress varies between 200 and $350 \mathrm{~N} / \mathrm{mm}^{2}$, which can be considered as a significant influence depending on the heat input parameter. If the amount of the molten material increases, the maximum longitudinal stress decreases. The transversal stresses do not differ so much, while the curves are nearly the same outside of the fusion zone. The graphs below show the stress results and the multiplication factors for each investigated parameters.

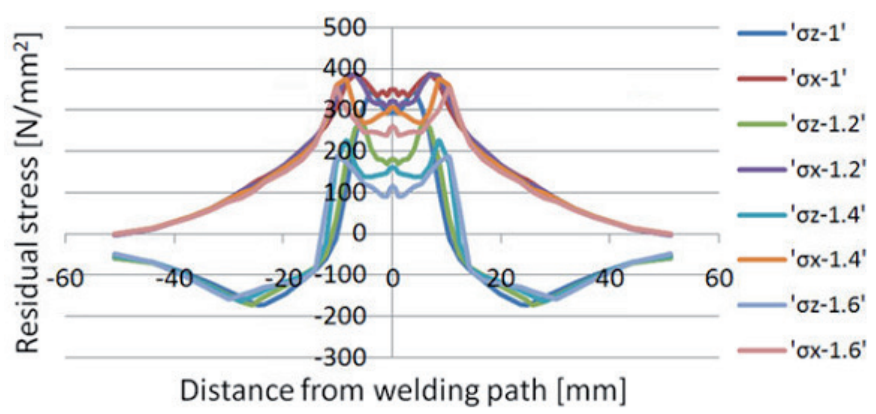

Fig. $20 \sigma_{x}$ and $\sigma_{z}$ residual stresses for different heat input parameters

The parametric study for the investigation of the welding speed results in similar curves as presented in Fig. 21 except only that the tendency is inverse. The results show the previous expectations that increasing welding speed increases the maximum tensile residual stresses, but it has smaller influence on the compressed part of the specimen.

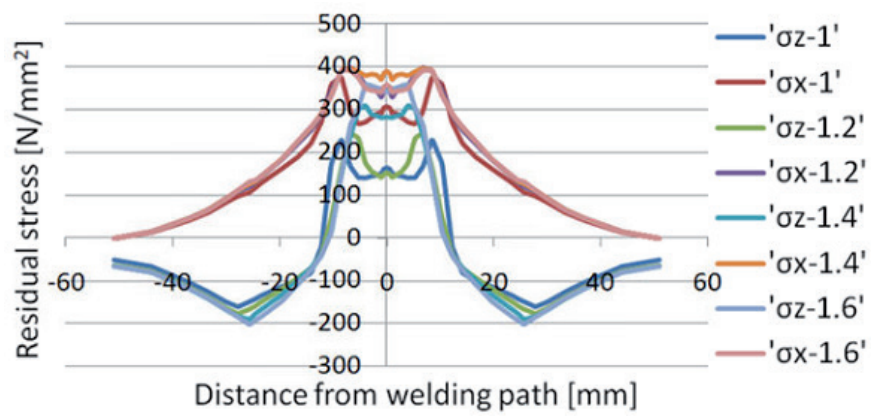

Fig. $21 \sigma_{\mathrm{x}}$ and $\sigma_{\mathrm{z}}$ residual stresses for different welding speed parameters

The advantage of Eurocode based material models is that the stress-strain curves can be easily modified by changing the value of the yield strength. The benefits are remarkable when investigating high strength steel structures and the residual stresses are to be determined. The current investigation is focusing on the residual stress distribution depending on the steel grade. The results of the simulations for different steel grades are presented in Fig. 22. 


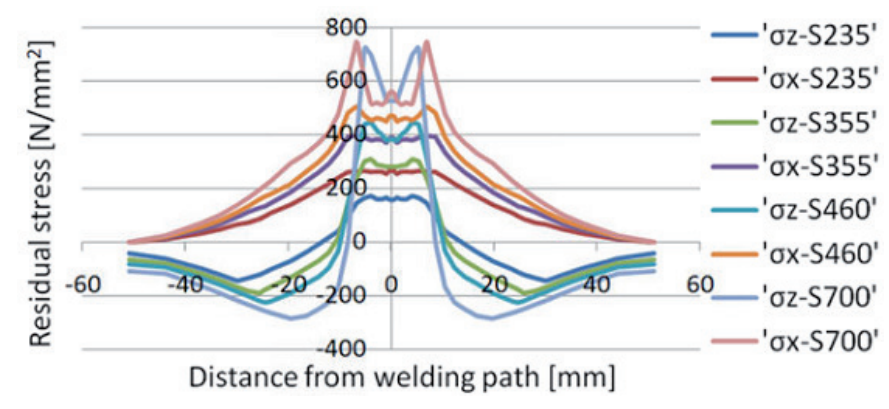

Fig. $22 \sigma_{\mathrm{x}}$ and $\sigma_{\mathrm{z}}$ residual stresses for different steel grades

The calculation results show that the maximum tensile residual stresses are between $f_{y}$ and $1.25 \cdot f_{y}$ for all the investigated steel grades. These results are in agreement with the general expectations, that the tensile residual stresses can be determined in function of the yield strength. Based on the current investigations this tendency is also showed for higher steel grades (up to S700) as well. The character of the curves is the same while the maximum tensile stress values differ for the different steel grades. At the same time it can be also observed, that there is a much smaller increase in the maximum compressive residual stresses and all the residual stress curves converge to the same compressive stress values. The same tendencies are observed in the laboratory tests of Somodi investigating high strength steel box section members [1].

\subsection{Local stability behaviour of welded box sections}

Welding simulations can be used in the development of the manufacturing process, but it is also applicable to determine the load carrying capacity of the produced steel member considering the actual residual stress distribution and initial imperfection shape. It means that the welding simulation can be also applied to improve current design methods used in the civil engineering practice or it can be used in FEM based design processes considering all the manufacturing effects on the load carrying capacity. Welding simulation can be also a tool to determine equivalent geometric imperfections for numerical simulations to ensure the required safety margin for stability problems of steel structures. Just as an example a local buckling behaviour of a welded box section is introduced in this paper to draw the attention to the applicability of welding simulations in the design of steel structures. Based on the verified numerical model the manufacturing process of a steel structural member (welded box section) is modelled and residual stresses and deformations are determined by numerical welding simulation. The buckling resistance of the box section under pure compression is determined by numerical simulations based on the equivalent geometric imperfections proposed by the EN1993-1-5 [2] and based on the results of the welding simulation as well. The buckling resistance of the two methods are compared and discussed while the application possibility and the advantages of the welding simulation in the FEM based design method are presented. Box girders are usually welded at the corners by fillet welds, but in this case a butt welded box section was analysed.

The width and height of the investigated box girder is $400 \mathrm{~mm}$ with plate thickness of $8 \mathrm{~mm}$. The applied steel material is S355. Having these geometries the investigated cross section belongs to class 4 under pure compression. The length of the specimen is set equal to the width to study only the local buckling behaviour and to eliminate global instabilities. All the four welds in the corners are welded within two weld passes. Tandem welding is modelled therefore planes of symmetry are applied in the finite element model. The symmetry conditions and the finite element mesh are shown in Fig. 23. In the numerical model 20-node solid brick elements are used. Several tack welds are defined to connect the steel plates before welding to eliminate rigid body motion at the beginning of the welding procedure.
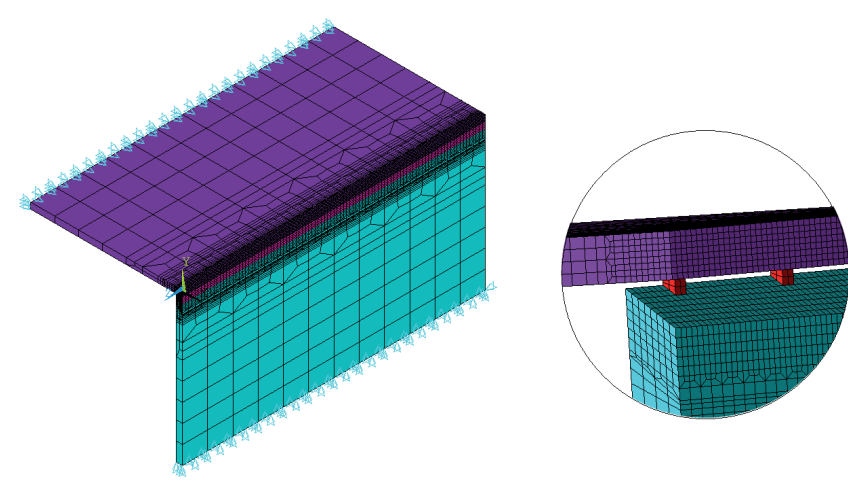

Fig. 23 Symmetry conditions and finite element mesh in the numerical model

The applied welding parameters and the parameters of the Goldak's heat source model are summarized in Table 3. The welding efficiency is assumed to be $85 \%$. The first welding path started at the beginning of the simulation process $(0 \mathrm{sec})$ and the second welding path started with $450 \mathrm{~s}$ later ensuring certain intermediate cooling of the specimen. The typical calculated transversal and longitudinal residual stress diagrams are presented in Fig. 24. These stress distributions have the same character observed in the case of the single butt welded plates. Tensile residual stresses are observed in the corner zone of the specimens in the heat affected zone, and compressive residual stresses are located in the middle of the sub-panels.

Table 3 Welding parameters of box section

\begin{tabular}{|c|c|c|c|c|c|c|c|}
\hline $\begin{array}{l}\text { Weld } \\
\text { pass }\end{array}$ & Process & $\begin{array}{l}\text { Current } \\
{[\mathrm{A}]}\end{array}$ & $\begin{array}{l}\text { Voltage } \\
{[\mathrm{V}]}\end{array}$ & $\begin{array}{l}\text { Speed } \\
{[\mathrm{mm} / \mathrm{min}]}\end{array}$ & $\begin{array}{l}\mathrm{a} \\
{[\mathrm{mm}]}\end{array}$ & $\begin{array}{l}\mathrm{b} \\
{[\mathrm{mm}]}\end{array}$ & $\begin{array}{l}\mathrm{c}_{\mathrm{f}} \\
{[\mathrm{mm}]}\end{array}$ \\
\hline 1 & MAG & 140 & 18 & 185 & 5 & 8 & 3 \\
\hline 2 & MAG & 200 & 18 & 185 & 6 & 5 & 4 \\
\hline
\end{tabular}



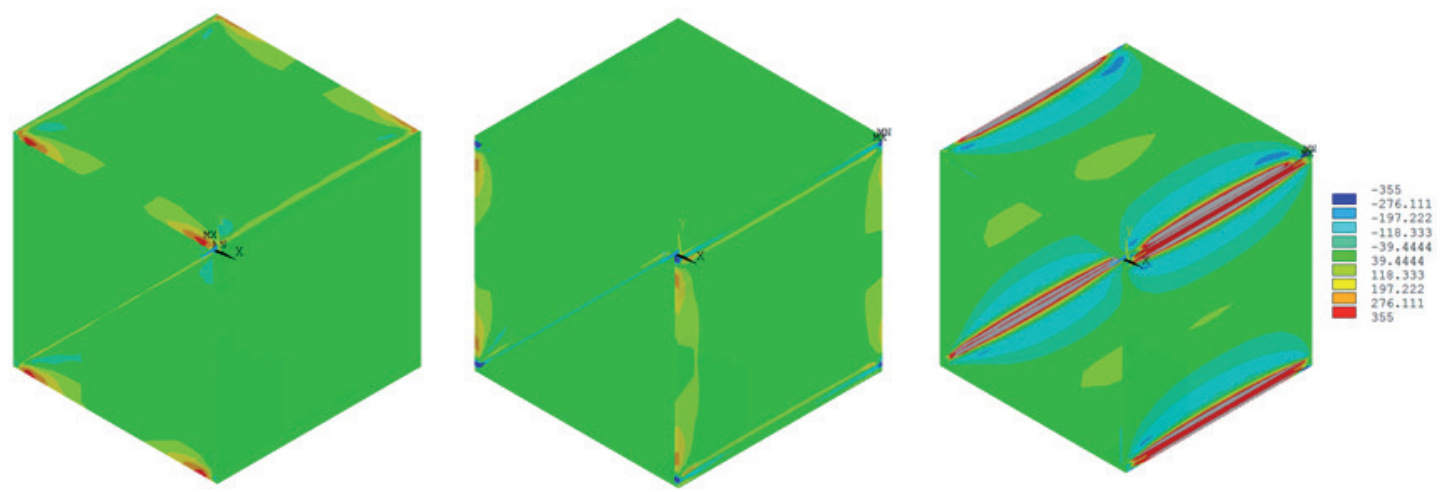

Fig. 24 Transversal and longitudinal residual stresses of a welded box section

Typical residual stress curves are presented in Figs. 26-27 for two analysed cross sections. Cross section 1 is located in the middle of the section and cross section 2 is located $100 \mathrm{~mm}$ far from the edge of the specimen as shown in Fig. 25. Residual stresses are evaluated on the inner and outer surfaces of the specimen as well.

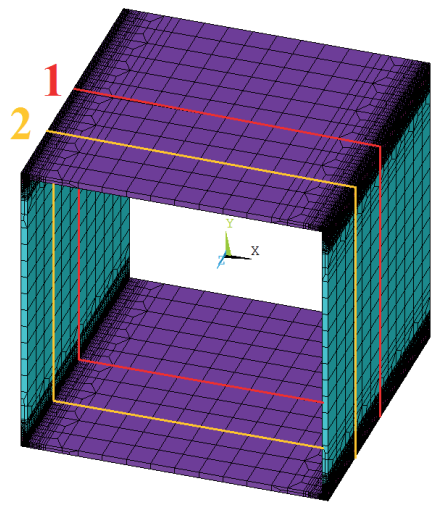

Fig. 25 Cross sections for residual stress evaluation

Transversal residual stresses are given by $\left(\sigma_{x}\right)$ and the longitudinal residual stresses are presented by $\left(\sigma_{z}\right)$ in Figs. 26-27. The corner zone between the flange and the web are signed by red dotted line on the diagrams. The numbers 1 and 2 refer to the analysed cross section number. The results show only a little difference between the stresses in the two different cross sections. The maximal tensile residual stresses are close to the yield strength of the applied material as expected based on the preliminary parametric studies. The compressive residual stresses can be different depending on the analysed cross section, which means that the length of the analysed girder can have influence on the residual stress distribution.

The results of the welding simulation are further used in the stability analysis. FEM based stability analysis of the box section girder under pure compression is executed using the residual stresses and residual deformations due to thermomechanical analysis (TM) and using the EN1993-1-5 [2] based equivalent geometric imperfections. The applied residual stress field and the geometric imperfections determined by the welding process are presented in Fig. 28 a) and b). The equivalent geometric imperfection (EC - EGI) based on the first buckling mode is presented in Fig. 28 c). Geometric and material nonlinear analysis is carried out using both imperfection types on the same model and the load-displacement curves are determined and compared. The calculated resistances by the GMNI analyses are also compared with the resistance of compression (EC - Nc,Rd) determined by EN1993-1-5 [2].

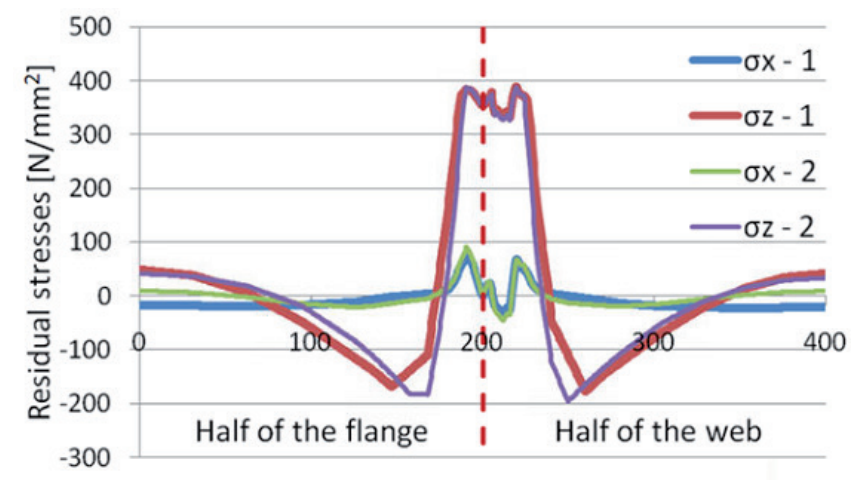

Fig. 26 Residual stresses on the outer surface

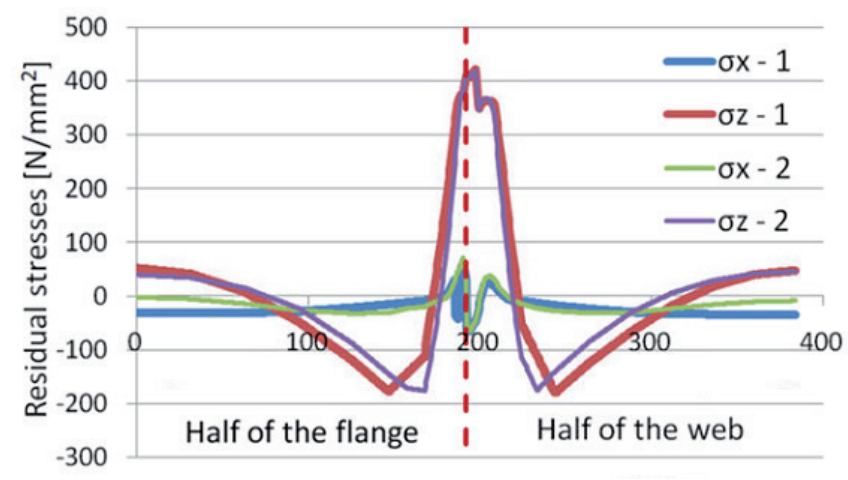

Fig. 27 Residual stresses on the inner surface

From the load-displacement curves the ultimate loads of all the analysed specimens are determined and compared. The relevant load - displacement curves and the ultimate failure mode for an S355 400x8 box section girder is presented in Fig. 29.

The load carrying capacity of the model considering the actual manufacturing process resulted in larger resistance (by $10 \%)$ than the simulation with equivalent geometric imperfections. It has to be mentioned that this statement strongly 
depends on the welding input parameters, it cannot be generalized based on the current investigation. But the calculation results show the application possibility of this method and the way how to increase the accuracy of the applied design procedure. This method also makes the improvement of the manufacturing process possible to produce steel members with smaller geometric imperfections and larger resistances. The developed approach is universal for any welded members irrespectively of the geometry. Arbitrary boundary conditions and loading cases can be considered in the GMNI analysis, therefore virtual experiments can be carried out on manufactured specimens.

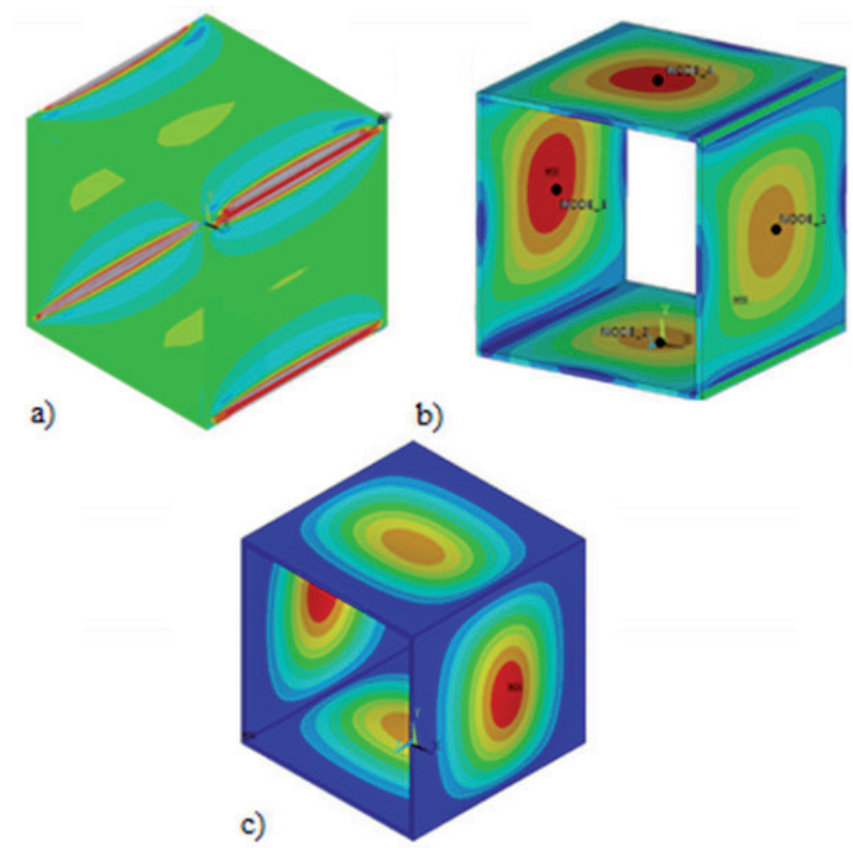

Fig. 28 a) Residual stresses; b) initial geometric imperfection and c) eigenshape for equivalent geometric imperfection

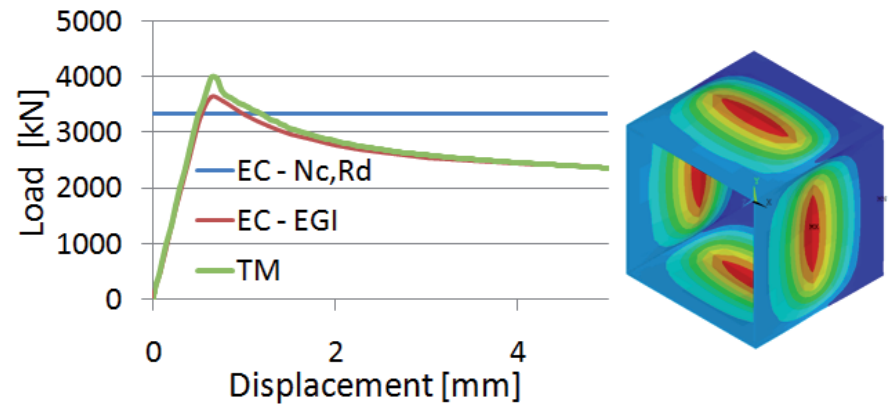

Fig. 29 Load-displacement curves and failure mode of the analysed specimen

\section{Conclusions}

Nowadays the numerical modelling makes it possible to simulate the welding process and to determine the residual stresses and the deformations of the structures due to the manufacturing procedure. If the welding process is simulated by FE calculations more accurate values of the residual stresses and initial imperfections can be implemented in the FEM based design method. On the other hand, the simulation of the welding procedure gives the possibility to improve the manufacturing process to reduce the residual stresses and geometric imperfections.

A finite element based design procedure is also presented in the current paper for welded structures. To be able to model different welding processes a common heat source is developed in ANSYS. The numerical model is able to consider the most important welding input parameters (welding speed, current, voltage and the efficiency) and welding processes. Since the material properties of the steel changes by the temperature therefore temperature dependent material properties are defined in the numerical model. An improved model is under development to be able to consider the effect of microstructural changes in hardness calculations and in the mechanical analysis as well.

The applied heat sources and the material model are verified by independent software tool (SYSWELD) and by own experimental results. Based on the verified numerical model the manufacturing process of a steel structural member (butt welded box section) is modelled and the residual stresses and the deformations are determined. The buckling resistance of the box section under pure compression is determined by numerical simulations based on the equivalent geometric imperfections proposed by EN1993-1-5 [2] and based on the results of the welding simulation. The buckling resistance of the two methods are compared and discussed while the application possibilities and the advantages of welding simulations in the FEM based design method are presented.

\section{Acknowledgement}

The presented research program is part of the "WeldImprove" R\&D project Nr. GOP-1.1.1-11-2012-0568, supported by the Új Széchenyi Terv [21]; the financial support is gratefully acknowledged. This paper was also supported by the János Bolyai Research Scholarship of the Hungarian Academy of Sciences.

\section{References}

[1] Somodi, B, Kövesdi, B. " Sajátfeszültségmérés nagyszilárdságú acél zártszelvényeken." (Residual stress measurements on high strength steel box sections.) In: XII. Magyar Mechanikai Konferencia. (XII. Hungarian Mechanical Conference ), Miskolc, Aug. 25-27, 2015. URL: http://www. mamek.uni-miskolc.hu/index.php/xii-mamek/index (in Hungarian)

[2] Eurocode 3 (EC3): European Committee for Standardization. EN19931-5:2005. Design of steel structures, Part 1-5 : General rules -Plated structural elements. European Committee for Standardization.

[3] ANSYS® v14.5, ANSYS Inc., Canonsburg, Pennsylvania, USA

[4] Lindgren, L. E. "Computational welding mechanics." CRC Press, Boca Raton, Florida, USA, 2007.

[5] Goldak, J. A., Akhlaghi M. "Computational Welding Mechanics." Springer Science + Business Media, Inc., New York, New York, USA. 2005.

[6] Nguyen, N. T. "Thermal Analysis of Welds." WIT Press, Southampton, UK. 2004.

[7] Néző, J. "Virtual Fabrication of Full Size Welded Steel Plate Girder Specimens." PhD thesis, Heriot-Watt University School of Engineering and Physical Sciences, Edinburgh, Scotland, UK. 2011. URL: http:// www.ros.hw.ac.uk/handle/10399/2433?show=full 
[8] Lindgren, L. E. "Finite element modelling and simulation of welding. Part I: Increased complexity." Journal of Thermal Stresses. 24(2), pp. 141-192. 2001. DOI: 10.1080/01495730150500442

[9] Mufti, R. A. "Mechanical and microstructural investigation of weld based rapid prototyping." PhD thesis. Ghulam Ishaq Khan Institute of Engineering Sciences and Technology, Swabi, Pakistan, 2008.

[10] Bradac, J. "Calibration of heat source model in numerical simulations of fusion welding." Machines, Technologies, Materials. 11, pp. 9-12. 2013. URL: http://mech-ing.com/journal/Archive/2013/11/76_Bradac.pdf

[11] Padmakumari, T., Venkatasairam, S. "Finite element analysis of EBW welded joint using SYSWELD." International Journal of Emerging Technology and Advanced Engineering. 3(2), pp. 335-340. 2013. URL: http://www.ijetae.com/files/Volume3Issue2/IJETAE_0213_57.pdf

[12] Anca, A., Cardona, A., Fachinotti. V. "Finite element modelling of welded joints." Mecánica Computacional. 27, pp. 1445-1470. 2008. URL: http:// www.cimec.org.ar/ojs/index.php/mc/article/viewFile/1498/1463

[13] Rontescu, C., Voiculescu, I., Iacobescu, G., Dumitrascu, C., Cicic, D. T. "Analysis of the thermal field for TIG welding by using infrared thermography." UPB Scientific Bulletin, Series D: Mechanical Engineering. 70(3), pp. 55-60. 2008. URL: http://www.scientificbulletin.upb.ro/ rev_docs_arhiva/full51364.pdf

[14] Eurocode 3 (EC3): European Committee for Standardization. EN19931-2:2005. Design of steel structures, Part 1-2 : General rules -Structural fire design. European Committee for Standardization.
[15] Krummenacker, J. "Simulation of the welding process of steel tube joints made of S355 and S690." Diploma, Karlsruher Institut für Technologie, Deutschland. 2011.

[16] Rhodin, M. "Calculation of welding deformations in a pipe flange." Master's thesis in Applied Mechanics. Chalmers University of Technology, Gothenburg, Sweden. p. 27. 2012. URL: http://publications.lib.chalmers. se/records/fulltext/162770.pdf

[17] Lindgren, L. E. "Finite element modelling and simulation of welding, Part 2: Improved material modelling." Journal of Thermal Stresses. 24(3), pp. 195-231. 2001. DOI: 10.1080/014957301300006380

[18] Francis, M., Rahman, S. "Probabilistic analysis of weld cracks in centercracked tension specimens." Computers and Structures. 76, pp. 483-506. 2000.

[19] Chang, P., Teng, T. "Numerical and experimental investigations on the residual stresses of the butt-welded joints." Computational Materials Science. 29(4), pp. 511-522. 2004. DOI: 10.1016/j.commatsci.2003.12.005

[20] SYSWELD Visual Environment 9.5, Virtual Manufacturing, Welding and Assembly, ESI Group.

[21] WeldImprove R\&D project Nr. GOP-1.1.1-11-2012-0568, supported by the Új Széchenyi Terv - Research report, Budapest University of Technology and Economics, Department of Structural Engineering, Budapest, 2015. 